\title{
A Review of Succession and Innovation in Family Business
}

\author{
Xinhua Yuan \\ School of Management, Jinan University, Guangzhou, China \\ Email:18720983907@163.com
}

How to cite this paper: Yuan, X.H. (2019) A Review of Succession and Innovation in Family Business. American Journal of Industrial and Business Management, 9, 974-990. https://doi.org/10.4236/ajibm.2019.94066

Received: March 22, 2019

Accepted: April 23, 2019

Published: April 26, 2019

Copyright (C) 2019 by author(s) and Scientific Research Publishing Inc. This work is licensed under the Creative Commons Attribution International License (CC BY 4.0).

http://creativecommons.org/licenses/by/4.0/

\begin{abstract}
Family business is an important part of the national economy and plays an important role in the development of social economy. The iterative process of technology and the new business model make the competition among enterprises increasingly fierce. If enterprises want to succeed in the fierce competition, they must consolidate and develop through innovation. At the same time, the phenomenon of intergenerational succession of Chinese family businesses is becoming more and more common. Recalling the research on intergenerational succession and innovation of family business, the existing research lacks a unified analytical framework, and the research results are scattered, fragmented, and systematic. This has largely restricted the depth of theoretical research in this field. This paper systematically sorts out intergenerational succession and innovation research. It has certain guiding significance for domestic family business succession practice and succession theory research. It will help researchers to better draw on the theoretical results in this field and lay the foundation for follow-up research.
\end{abstract}

\section{Keywords}

Family Business, Innovation, Succession, Review

\section{Introduction}

Innovation is the fundamental driving force for the development of modern enterprises and the source of value creation. Under the background of comprehensively deepening reforms and accelerating economic transformation, enterprises can achieve sustainable development and value breakthroughs through continuous innovation. Enterprise innovation is the key to ensuring sustainable competitive advantage. For our family business, innovation is an urgent choice in order to adapt to the current market environment and achieve further devel- 
opment. In order to maintain long-term development, especially in the case of multi-generational family members, family businesses often need to innovate to avoid recession and death. However, studies have shown that family businesses generally show a risk aversion tendency to reduce innovation in order to reduce social innovation. From the perspective of family business ownership and management rights, the rise of equity concentration in family businesses has a significant hindrance to innovation investment, and family management rights have a significant negative impact on family business innovation capabilities.

Chinese family business has entered the peak period of the handover of the first and second generation family leaders. According to the statistics released by Forbes (Chinese version) in 2013, 36.4\% of the 711 family-owned companies listed on the A-share market have one or two generations of simultaneous employment. Among them, 16.99\% of enterprises have been taken over by the second generation, and this situation will become more common over time. Intergenerational succession has a direct impact on innovation input, innovation activities and innovation output. Hauck \& Prügl (2015) propose that in order to make the intergenerational succession go smoothly, the incumbent will support innovation in the important stage of intergenerational succession. Zhou Lixin (2014) shows that the family algebra of the management enterprise has a significant positive impact on the innovation ability of the family business. Intergenerational succession provides an opportunity for family businesses to open closed borders and enhance their ability to innovate.

Reviewing the literature on the intergenerational succession of family businesses, although there are so many documents on the succession of family businesses, it can be found that research topics focus on intergenerational succession system design. The process and method of succession, the successor and leadership development, the corporate governance after succession, the existing control and leadership of the enterprise are transferred between generations, and the intergenerational succession affects the performance of the enterprise. However, the intergenerational succession of family businesses has less research on enterprise innovation. Looking back at the research on intergenerational succession and innovation of family business, we can find that different scholars have explored the influence of intergenerational succession on innovation from different angles. Some scholars have explored the influence of a series of non-economic factors on the successor's willingness to innovate after the intergenerational succession from the perspective of social emotional wealth [1]. From the perspective of market orientation, scholars have found that after intergenerational succession, the market orientation of inheritors and successors is different, which further affects the degree of innovation of family businesses. Looking at the research results of intergenerational succession and innovation of family businesses, it is not difficult to find that research in this area is still scarce. Due to the lack of a unified analytical framework, the existing research results are scattered, fragmented, and lack of systemization, which largely restricts the deepening of theoretical research in this field. 
This paper systematically combs intergenerational succession and innovation research, and has certain guiding significance for domestic family business succession practice and succession theory research. It will help researchers to better draw on the theoretical results in this field and lay the foundation for follow-up research.

The rest of this article is divided into four sections. In the first part, we sort out the definition of intergenerational inheritance and discuss the importance of intergenerational inheritance of family business. The second part of the thesis reviews and summarizes the concept of family business innovation and the perspective of innovation. Then, the third part of the thesis combines the real background and systematically sorts out the research context of the relationship between family business's intergenerational inheritance and innovation. Based on the review of literature research, the paper summarizes the characteristics and differences of scholars at home and abroad when studying the topic, and looks forward to the future research, in order to provide reference and reference for the future research of intergenerational inheritance and innovation in China.

\section{Intergenerational Succession}

The intergenerational succession of a family business refers to the transmission of the enterprise between generations and generations. It transmits a variety of forms. It can be parent pass child, parent pass nephew, or grandparent pass grandchild, etc. In short, intergenerational succession is concentrated in the replacement of family business leaders. The intergenerational succession of family business power refers to the process in which the ownership and management rights of the enterprise are passed from the head of the family to the heir. Succession includes company ownership and control, as well as implicit social networks, leadership authority, entrepreneurship [2]. It began with the successor as a newcomer to enter the enterprise to undertake the work, regardless of the position of the position, whether the position is important or not, ending with the heir to become the city-level leader to control the enterprise, the older generation of leaders retired to the second line. The duration of intergenerational transmission of the entire family business will take at least several years, and even more so for decades.

In the initial stage of Chinese market economy development, the family business that has started and succeeded in succession may face more complicated market environment and more fierce competition in the industry. The sustainable development of enterprises has higher requirements for their knowledge, ability and quality. At the same time, the differences in educational background, values, and business ideas of the second generation are likely to lead to internal contradictions in family businesses. Therefore, the academic research on succession mostly focuses on slowing down conflicts and ensuring the stable development of family businesses. Wan Shengli (2014) in the literature research of family business succession pointed out that the current view of the process of suc- 
cession has been initially established by the academic circles, focusing on the influencing factors of the three periods before, during and after the succession. And the succession of conflicts, risk studies, the focus is on mitigating conflicts by controlling relevant factors to ensure smooth progress of succession.

Since ancient times, China has had the saying that "Wealth does not pass three generations". The popularity of this "mantra" also reflects from one aspect that intergenerational succession is considered by most people to be important. Of course, some people in the academic world think that intergenerational succession is irrelevant. Kaye (1998) believes that the intergenerational succession of the family is not necessary. The family does not even need to maintain the ownership of the enterprise. In the long run, family management must be formalized. Despite this, the mainstream voice still believes that intergenerational succession is an important issue in the development of family businesses. Whether this problem can be handled well has an important impact on the long-term development of family businesses. And for a long period of time, this will be the main way for family businesses to pass.

Why should the turnover of family business leaders be carried out among family members? Chen Ling (2003) attributed the family business to the influence of traditional culture, he believes that "The sub-father business model" extrapolated by the differential order pattern is the mainstream model for the succession of Chinese family businesses. Foreign economists' discussion of this issue focuses on the institutional roots and nature of the family phenomenon. Ralph Chami (1999) emphasizes the market constraints faced by family businesses, and family businesses have to find successors within the family. Lee et al. (2003) also believes that the reason why family businesses find successors within the family is not because of the nepotism, but because of the rational choice of the firm, because the family business is a heterogeneous organization in the family. Choosing successors within the company is good for companies to avoid risks and avoid the problem of agents that family businesses may encounter.

In China during the economic transition period, the succession of family businesses within the family can largely avoid the impact of "lack of trust" and thus reduce transaction costs. Intergenerational succession will also be the main form of replacement of family business leaders for a long period of time. As the decision-maker and executor at the highest level of the company, the new successor is responsible for taking the opportunity to innovate, leading the company to acquire core competence to occupy a favorable competitive position. However, they are often hindered by many factors, such as the practice of the company's long-term development, political resistance, corporate culture and corporate asset specificity, which are difficult to trigger big innovations. Therefore, the replacement of new leaders in the family business has become an important way for the company to innovate.

\section{Family Business Innovation}

A large number of scholars have given different definitions of innovation. Some 
scholars have pointed out that innovation is the process, result and product of developing new products or improving existing processes. Compared to the creative generation phase, the innovation phase emphasizes the process of implementing ideas in order to obtain better procedures, practices, or products. Although innovation is a process of pursuing new procedures, products, etc., innovation still relies on the mastery of existing knowledge bases, and innovation relies on familiarity with existing company operations. User innovation and so on even emphasize the in-depth analysis of existing star users.

Innovation has always maintained its duality for family businesses. On the one hand, innovation not only promotes the accumulation of competitive advantage, but also benefits corporate performance and long-term development. The goal and vision of spanning multiple generations of long-term development is an important feature that distinguishes between family and non-family businesses. Therefore, innovation is important for family businesses [3]. On the other hand, innovation as a risk behavior is often described as incompatible with family business, because family businesses are characterized by risk aversion, they are not willing to sacrifice stable development to achieve rapid performance improvement.

At present, the research on the effect of innovation can be divided into four perspectives: behavioral theory perspective, resource and capability perspective, agency theory perspective and upper echelons theoretical perspective. From the perspective of behavioral theory, it grasps the law of people's behavior through the study of human psychological activities, and seeks the strategy of family enterprise innovation. The perspective of resources and capabilities starts from the enterprise itself and explores the impact of the resources and capabilities owned by the enterprise on innovation. The perspective of agency theory is to study how the interaction between principals and agents affects enterprise innovation in the context of conflicts of interests and information asymmetry. From the perspective of micro-levels, the upper echelons theoretical perspective explores the power alliances in enterprises, and the influence of the characteristics and composition of some power roles on innovation.

Corporate Behavior Theory (Cyert and March, 1963) points out that the incentives and goals of key stakeholders determine corporate behavior. If compared with non-family businesses, family businesses are more willing to create and protect social emotional wealth for families [4]. There is research evidence that family businesses have shown strong concern for potential loss of control in the pursuit of social emotional wealth. The family business's aversion to loss control may complicate the relationship with external partners. When it is necessary to transfer shares to external parties such as venture capitalists or institutional investors, the protection of their social and emotional wealth by family businesses may reduce the propensity to achieve innovation. In this context, the family tends to ensure that the company's control is held by family members. This has led to a high probability of hiring potentially unqualified family CEOs, which may limit the ability of companies to invest in value-added innovation 
and influence their innovation strategies. But on the other hand, although not good enough family heirs may not be able to create valuable innovations for their families on their own, But because of their embedded family relationships with family heirs, family businesses will ensure that innovative initiatives taken by new family CEOs succeed, guiding them to innovate independently or coordinate top-level team management to promote effective innovation.

The resource-based view (RBV) believes that innovation is becoming more necessary because internal resources are not sufficient to achieve the company's goals. At the same time, the company's good absorption capacity increases the return of the company's access to external resources. Complementary resources are a key driver of interfirm cooperation.

From a capability-based view, family businesses may also have unique organizational innovation capabilities, such as the ability to resort to debt or inadequate external equity financing. This may limit their response to potential innovation opportunities. At the same time, the minimalist tendencies associated with family governance prototypes do require careful conservation of resources, which may prevent family businesses from tempting to experiment with expensive and new technological opportunities.

From the perspective of agency theory, family members have specific control over the company's assets due to family ownership. On this basis, family members can use these rights to influence key decisions in the organization. The unity of ownership and control of family governance concentrates organizational power on entrepreneur-managers or family members. This leads to the dominant tendencies of individualism [5], that is to say, this gives entrepreneurs or their families extremely powerful power and legitimacy within the organization, This allows the agent to run with less internal and external permissions, limiting administrative privileges in other governance prototypes.

The research framework of upper echelons theory is based on the study of executive's orientation. After Hambrick \& Mason (1984) proposed upper echelons theory, a large number of studies rely on high-order theory to explore the influence of CEO and other characteristics on innovation. The core of upper echelons theory is 1) the behavior of senior managers is based on the senior management's interpretation of the status quo of the strategy; 2) the interpretation of the current status of the individual executives is a function of the experience, values and personality of the top management. Crossland et al. (2014) found that CEO's career variety refers to the significant positive impact of innovation on career and institutional experience before executives become CEOs.

\section{Intergenerational Succession and Innovation}

Through the reviewing of previous research, we organize research through three levels of analysis: environment, organization, and individual. Each level is an important summary of existing research and then categorized by key variables from previous research reports to explore the impact of intergenerational suc- 
cession on innovation.

\subsection{Environmental Level}

\subsubsection{Environmental Dynamics}

Dynamics refers to the uncertainty and turbulence of market and industrial conditions, including state of the art and overall economic performance. Environmental dynamics are positively related to CEO succession and innovation, especially from the same industry to choose a new CEO. This is consistent with the theory of resource dependence, which indicates that competitive and uncertain external conditions make it more likely to perform succession. Because companies try to match the characteristics of their successors with CEO positions, For example, by appointing a new CEO to appropriately change the organization's power structure, it can be used as a mechanism to adapt to environmental emergencies. Because this requires people familiar with the industry, the possibility of hiring CEOs in the industry is also increasing in rapid technological change. For companies in the dynamic industry, traditional prescriptions are entrepreneurially oriented, often including innovative research and development of new products to achieve or maintain a good competitive position.

Family businesses that avoid risk should be aware that in a hostile environment, if a company wants to grow, it must take a certain level of risk. In addition, the time span of family business goals needs to be adapted to the speed of their respective markets. In a rapidly changing environment, long-term plans can become obsolete, and in a slow-paced market, projects may take more time to grow. As the rate of change in the environment changes over time, it is important to establish governance and management practices that predict and adapt to market changes.

However, some researchers have found that there is no evidence that the concept of fierce competition in the industry is related to innovation, and the assumption that environmental dynamics will positively influence innovation to achieve business growth cannot be supported.

\subsubsection{Industry Type}

When products and processes between industries are easily imitated, companies tend to invest less in R\&D and engage in less international activities because any achievable competitive advantage can only be exploited in a short period of time. But it is these hostile environments that make innovation important for developing new resources and processes, thereby mitigating the negative effects of imitation threats. For example, the manufacturing environment is described as having a high degree of uncertainty, and companies must be alert to the need for innovation or demise [6]. Scherer argues that this issue should be conceived based on technical opportunities in different industries. Compared with a more stable environment, in industries with rapid and broad knowledge development, innovation output is greater. More importantly, the degree of exploration in a family business, that is, the generation of new knowledge rather than the use of 
existing knowledge, depends on the overall innovation of the industry. In a more homogeneous industry, external successors are more likely than internal successors because external candidates have a better understanding of production technology and product markets. However, the higher the industry competition, the greater the possibility of internal succession.

According to survey data from 845 manufacturing companies in Canada, industries with higher R\&D intensity have higher corporate innovation capabilities. In the high-tech manufacturing industry, the percentage of companies that introduce the country's or the world's first innovative products is more than twice that of the low-tech industry [7]. The two-way interaction between intellectual assets and innovation is important in the high-tech field, and in low-tech areas, the interaction between training and innovation is important.

\subsection{Organizational Level}

\subsubsection{Enterprise Knowledge and Knowledge Transfer}

Knowledge is critical to the innovation process. Whether knowledge is internally generated or externally acquired, the knowledge of the organization determines what it can do. Dierickx and Cool classify the enterprise's knowledge assets into stocks and flows. The internal stock capacity library brings together individuals' knowledge and abilities-the intellectual capital or organizational memory of the firm. The stock covers declarative knowledge and procedural knowledge.

The resource-based view is unambiguous in the role of knowledge in creating competitive advantage. As an asset, knowledge can have the characteristics of value, scarcity, imitation and organizational input. These attributes are key to achieving superior business performance. Knowledge is considered to be a key resource that makes a company different from other companies. It can constrain and guide the company's ability to take action and distinguish it from competitors. Knowledge is a unique resource that can be used by multiple participants or groups within an organization. Knowledge assets can increase opportunities for companies to create and implement innovation. For example, Tsai found that internal units with higher levels of competence are more likely to introduce innovation than lower units. Companies continue to increase their stock of knowledge assets by investing in resource flows. Over time, the stock of knowledge has gradually declined, losing the ability to give enterprises a competitive advantage. Some knowledge stocks need to be maintained, because once they are discarded, they cannot be re-released, but they are expensive to maintain, require time and effort, professionals or frequent new technologies and training.

When companies learn to expand or change their knowledge stock. Training stimulates internal knowledge flow and guides future actions without limiting them. This increases the distribution of knowledge among members of the organization, promotes the emergence of common meanings, and allows existing capabilities to be synthesized and reconfigured. The process of transferring, interacting, sharing and transforming knowledge is critical to any company be- 
cause of its impact on innovation. These processes are particularly challenging in the family business succession process. However, few studies examine the impact of knowledge transfer on innovation in succession.

The internal knowledge learning of the successor refers to the knowledge from the inside of the enterprise that the successor has learned. The inheritor's guidance and apprenticeship model for the successor can not only help the successor to become familiar with the company's internal business, but also help to grasp the existing corporate culture and absorb it, the tacit knowledge of the successor. Successors have a certain amount of internal knowledge that can promote innovation. However, when the successor learns excessive internal knowledge, the successor is easy to form a fixed thinking, resulting in path dependence, etc., which is not conducive to enterprise innovation.

Further, in the knowledge transfer process of family business, there is not only the successor's learning of internal knowledge, but also the successor's learning of external knowledge. When considering the external knowledge of the successor, on the one hand, external knowledge can help the successor to make better use of internal knowledge innovation. On the other hand, external knowledge can also help the successor to open up ideas, not be bound by the old thinking mode, and still maintain the ability to innovate even when learning a lot of internal knowledge. In other words, when external knowledge is at a higher level, internal knowledge learning of the successor will positively influence enterprise innovation. When external knowledge is at a lower level, the internal knowledge learning of the successor will first positively affect the enterprise innovation. With the improvement of internal knowledge learning, the role of internal knowledge is gradually reflected, and internal knowledge learning of successors will negatively affect enterprise innovation. Some scholars have pointed out that the older generation's training of young family members can help them learn the internal knowledge of the company and how the original business works. But it does not help successors learn how to discover new opportunities from existing business activities and use these new opportunities to create business value and generate competitive advantage.

\subsubsection{Organizational Market Orientation}

Deshpandé and Kohli and Jaworski argue that market-oriented behavior leads to superior innovation and greater innovation success. In addition, pointed out: "The key factor determining the ability of a company to successfully develop and commercialize innovation is how to understand customer needs". Market orientation creates a deep understanding of the customer and a detailed understanding of the market. This enhances management's influence on the effectiveness of innovation activities, reducing the incidence of innovation failures, pointed out that market-oriented enterprise customer knowledge can help companies develop more effective products, better positioning and better market choices. For every dimension of market orientation, there are different arguments and mechanisms about why it is related to innovation. 
Responsive market orientation has a positive impact on innovation through empirical effects. Responsive market orientation focuses on the company's current knowledge and experience, and increasing familiarity with existing areas reduces risk and error potential in the innovation process and enhances the likelihood of innovation success. The Proactive market orientation is actively linked to innovation and identifies potential customer needs by working closely with leading users and conducting market practices. Focusing on potential market needs alerts companies to new market and technology developments and increases the company's ability to add this new market information to innovation development. This leads to innovation and unique benefits. In addition, exploring previously unknown areas of knowledge is positively related to new breakthrough innovations.

Emerging market orientation is positively related to innovation, as identifying new customer segments will lead to the development of new products and services, especially new products and services for these customer segments. Christensen pointed out that understanding emerging customer groups is critical to innovation. Govindarajan and Kopalle argue that market orientation for emerging customer segments rather than existing customer segments enables companies to develop breakthrough innovations. Therefore, when a family business provides evidence of responsiveness, initiative, and emerging market-oriented behavior, it has a positive impact on innovation.

\subsubsection{Family Ownership}

Ownership types can influence business decisions because they are associated with varying degrees of risk aversion and the company's resource endowments. Therefore, the degree of family ownership may affect the company's attitude towards risk, which may influence strategic decision-making from the perspective of risk and resource acquisition, and affect the choice of innovation strategy. Family ownership can create an altruistic, loyal, committed, family-connected and stable organizational culture. These characteristics in turn reduce the motivation of individual opportunism and encourage attention to the long-term interests of the business and its shareholders. Therefore, family business managers are long-term and are unlikely to make short-term investment decisions and innovation decisions. Since R\&D investment may have a competitive advantage associated with long-term success, family business managers may choose to adopt this approach despite the associated risks. Sirmon and Hitt believe that family companies with a broader investment horizon are more willing to pursue more innovative strategies and are more willing to choose to cooperate with external innovation. Innovative inputs constitute the trust, understanding and support of risk among family members [8]. Family ownership that is closely linked between family members may encourage mutual sharing of information and experience. This intensive communication enables family members to have a clear understanding of the company's mission and recognizes each member's ability to deal with problems, thereby promoting the family business's courage to 
undertake potentially profitable innovations, risk. In addition, family businesses are interested in investing time and money in providing potentially sustainable linkages to resource acquisition. For example, close relationships with financial institutions may help to obtain financial capital, allowing for more innovative strategies to better increase R\&D investment.

However, some studies have pointed out that family ownership has a negative impact on corporate innovation behavior. After the development of the family business, the company already has a certain asset scale. They hope to establish a lasting and stable heritage for future generations. Therefore, family managers are often risk aversion, and focus on stability and survival. Schulze, Lubatkin, Dino, and Buchholtz also present a similar view: they say that family members may block new careers because of potential threats to the status quo and family wealth. As innovations such as $\mathrm{R} \& \mathrm{D}$ investment deprive family members of short-term wealth, the uncertainty involved may threaten the viability of firms, Family managers may try to limit investment in risk and long-term research and development projects, reduce corporate innovation behavior, protect the welfare of their family members, and ensure long-term business. As a result, family managers may consider short-term horizons and may be less likely to pursue risky but promising growth opportunities [9]. Family goals such as maintaining family employment and family control are often more important than corporate goals such as maximizing profit, growth and innovation. In addition, family businesses tend to appoint family members to take up management positions rather than hiring more qualified outsiders. This also affects management risk and the ability to adjust corporate resources and innovation activities.

The desire to maintain the current stability situation may lead to financial cautious family members. Sirmon and Hitt and Freandez and Nieto argue that family businesses have limited external sources of financial capital because they are reluctant to dilute household ownership and tend to rely on corporate-generated family resources or institutionally funded funds. However, limited R\&D cash flows may be detrimental to the formation and accumulation of R\&D knowledge through acquisitions, launching new products or enhancing knowledge bases. Due to the limited source of funds allocated, companies may not be able to continue to invest in $\mathrm{R} \& \mathrm{D}$ and are unable to make more innovative attempts to increase the risk of failure. Family members may be cautious about company resources because they make decisions through family personal wealth [10]. Family members tend to earn resources seriously and may motivate them to use company resources effectively. Durand and Vargas suggest that family members have incentives to increase the effective use of resources because they share a common destiny. Similarly, Carney argues that due to family members' requirements for the company's residual value, strong incentives closely monitor managers to ensure resource conservation and intensive use. Based on the tendency of simplicity, family businesses may be more efficient in using $\mathrm{R} \& \mathrm{D}$ investment, and non-family businesses may require less $\mathrm{R} \& \mathrm{D}$. 


\subsection{Personal Level}

\subsubsection{Controlling Generation}

Miller described the family members of the early generation as a family business with strong emotional attachment to each other. Family businesses have different innovation orientations at different intergenerational stages. Schumpeter's innovative perspective points out that the way companies manage resources and develop capabilities over time can impact innovation. Since the control generation affects the management and structure of the family business, it can be expected to have an impact on the innovation of the family business.

There are differences in the innovation culture between family businesses in the same generation. An empirical study by Zahra emphasizes that family businesses have more innovation-oriented cultures when they are involved in the management of the company. An innovation-oriented culture emphasizes creativity and creativity for innovation. This has had a positive impact on the innovation of family businesses. In addition, the next generation is often seen as the driving factor behind innovation and the identification of entrepreneurial opportunities [11]. They also tend to promote the development of new things. The centralized power and decision-making power of the founders of the first generation of family businesses negatively affected innovation. Conversely, in future generations of family businesses, all family members are more likely to participate in decision-making on an equal footing, which is good for innovation. In addition, more professionalism in family businesses managed by future generations is considered to be beneficial to entrepreneurial creation. All of this makes us expect that when the future generations manage the family business, the innovation ability of the family business will increase.

\subsubsection{Founder}

Family founders play an important role in influencing family business innovation. This is because the family's founder's close family relationship with his heirs is more likely to provide help to the successor than to discipline. With this assistance, the founder distinguishes outstanding innovation projects from bad innovation projects. The founders better understand the value-added nature of risk and growth innovation projects. In addition, founders can play a coordinating role because they often have a close relationship with board members and have a paternal status in family authority and respect [9]. Board members are often reluctant to compromise the relationship with the founder by challenging the founder's ruling order. Family founders with power and attention on the board will be able to better assist family successors in pursuing value-added innovation by coordinating board and decision-making processes.

On the other hand, family founders may be inclined to avoid risks and curb resources for pursuing risk-innovative projects that may threaten their family's wealth, thereby avoiding the ability of family-controlled companies. This can be done by preventing the successor from ruling the board's agenda to invest in risky but valuable innovations. In addition, because the founder's continued in- 
fluence may make the successor feel inadequately controlled by the company, the founder on the board may lead to serious conflicts between the family founder and the successor. While collaboration is important for successful innovation, successors may not be able to make effective investments or implement valuable innovation projects due to differences of opinion with the founders [12].

Despite these potential negative effects, a founder of entrepreneurial vision based on parental style can not only weaken the conflicts of board members on the board of directors, but it also helps family successors to invest in value-added innovation rather than suppressing such investment. In contrast, when a family founder leaves the board, he may not be able to directly play a guiding or bridging role, so the company's innovation efficiency by sub-optimal successors may be potentially deteriorating. In fact, Ensley and Pearson found that parent companies whose founders are still on the board are more successful than other family and non-family businesses. Found that the family succession CEO without the founder of the board of directors had a lower response to the innovation announcement than the company whose founder served as the family's successor to the board of directors.

\subsubsection{Successor}

CEO risk-taking refers to the CEO's willingness to take advantage of opportunities to invest large amounts of resources or engage in behaviors with uncertain outcomes, identified as the driving force for innovation [13], studied the relationship between successor risk-taking and innovation. The more risky the successor is, the more likely it is to influence product portfolio innovation, leading to greater innovation. Ownership of TMT family members will interact with $\mathrm{CEO}$ risk-taking tendencies to influence innovation in new product portfolios. Specifically, if the TMT family members have a higher level of ownership, the relationship between CEO risk tolerance and new product portfolio innovation is weak. In addition, the impact of CEO risk tolerance on new product portfolio innovation is stronger in the early stage family business. Knight found a positive correlation between manager's risk-taking and innovation task performance. Gille yet found evidence that executive risk trends have a strong positive impact on innovation performance. Ling supports this view, indicating that executives' risk propensity is positively related to entrepreneurship. In this study, CEO risk-taking tendencies are associated with new product portfolio innovations as a central outcome of innovation activities and as a measure of corporate risk behavior. Previous research has focused on organizing background predictions for innovation-related family business behaviors, ignoring the influence of CEOs' preferences and behaviors. The successor's time-oriented, that is, the part of time that is important to the leader may influence the time and intensity of innovation. Time-sensitive leaders may launch major innovations shortly after taking office, and future-oriented leaders often spend time and promote innovation over longer periods of time [14]. 
Successors are divided into internal succession and external succession. Most scholars believe that external succession will lead to more innovation. First, internal successors are based on their original information base in the organization and their grasp of the competitive environment. Enterprise-specific cognitive orientation and participation in previous strategy development allow internal CEOs to retain enterprise-specific knowledge and use resources without innovation. Second, the internal successor, before the succession of the CEO, incorporated the company culture and had the opportunity to work after succession. This reduces the time required to learn job requirements, and internal corporate knowledge and the plane learning curve also reduce disruption and thus reduce innovation. In addition, the external CEO success rate rose from 14\% in 2007 to $29 \%$ in 2012, and the increasing success of external CEOs is to initiate change and innovate. However, some researchers have found that internal successors lead to greater innovation. Believes that relying on existing relationships, internal CEOs can use cohesion and communication to increase innovation, while external successors are scarce in the company and it is difficult to launch enough supporters to innovate. There are also researchers who study the relationship between intergenerational succession and innovation from the perspective of expected succession and unintended succession. Chalus research finds unsuccessful succession of family business successors. After succession, they are more willing to take risks and seek new business opportunities. They can go beyond family routines and innovate without hesitation [15].

\section{Conclusion and the Future Research Directions}

This paper reviews the concepts of intergenerational succession and innovation of family business by reviewing the predecessors' literature. The predecessors' research perspectives on family business innovation mainly focus on behavioral theory perspective, resource and capability perspective, agency theory perspective and upper echelons theory perspective. The antecedent research on family business innovation is divided into three levels: environment, organization and individual, and the environmental level includes environmental dynamics and industry types. Organizational level includes enterprise knowledge and knowledge transfer organizational market orientation and family ownership. The personal dimension includes controlling generation, successor and founder factors. In addition, this paper proposes the following research directions for family business innovation in the future.

\subsection{Social Emotional Wealth on Innovation}

Management research shows that companies are increasingly pursuing a collaborative innovation process that systematically captures and leverages external knowledge and leverages technology through external market channels. Therefore, predecessors have carried out a lot of theoretical and empirical research to investigate the advantages and disadvantages and factors that affect the willing- 
ness and ability of enterprises to innovate. Behavioral theory is the basis of family business theory. If compared with non-family businesses, family businesses are more willing to create and protect social emotional wealth for families. Evidence suggests that family businesses have expressed strong concerns about potential loss of control in the pursuit of socially emotional wealth. Such concerns may complicate partnerships with external partners, and innovation means control of product technology trajectories. On the other hand, if we adopt a resource-based view perspective, using external social capital, the family business can cultivate and develop superior capabilities with long-term relationships with stakeholders: Gómez-Mejía, Nunez Nickel, \& Gutierrez (2001), and more tendencies to improve relationships with external parties and family reputation, which can enhance the open innovation willingness and ability of family businesses to interact closely with external partners.

Therefore, the tendency to acquire and commercialize knowledge outside the company's boundaries may vary between family and non-family businesses. Understanding the willingness of family and non-family businesses to collaborate on technological innovation is an interesting approach to future research.

\subsection{The Impact of Family Members on Innovation}

Due to its particularity, the family business still has an inseparable link between the successor and the predecessor and the family. Many decisions of the successor will also be affected by them. Therefore, it is encouraged to further analyze the impact of family on innovation, especially to determine the size of the firm, differences in family composition or differences in the legal structure of the company. Although small companies have fewer resources than large companies, they may benefit from more interaction and closer relationships between family members and employees, which may translate into greater innovation. In terms of family dynamics, little is known about how siblings and spouses, Therefore, we know very little about gender and its impact on family business innovation. So far, family members who are not actively involved in corporate governance or management, such as the spouse of a family manager, may be the driving force for innovation or the motivation to oppose innovation, not at all concerned. Finally, when we look for different answers about why family businesses are different, it is not enough to make implicit assumptions simply because some of the reasons may have been cited in previous studies. They must actually be measured. Therefore, how to find out how to use all aspects of the family and its impact on innovation will be the challenge of the future.

\subsection{Leader on Innovation}

Since Hambrick and Mason proposed that population characteristics can be used as an alternative to individual cognitive bases because of the difficulty in obtaining data on actual psychological characteristics, research has consistently used these characteristics as indicators of cognition. However, evidence of the 
relationship between personal cognitive base and demographic characteristics is at best ambiguous. Therefore, research requires a more direct measurement of the cognitive base of individuals. The CEO's psychology literature has produced a variety of personality traits, such as core self-evaluation or narcissism, this may be important to increase our understanding of the LSSC relationship. Although empirical evidence supports these personality traits may affect LSSC relationships. The use of a comprehensive and effective psychological framework to investigate the relationship between the personality traits of new leaders and the strategic changes following the succession seems to be more promising.

\section{Conflicts of Interest}

The author declares no conflicts of interest regarding the publication of this paper.

\section{References}

[1] Hauck, J. and Prügl, R. (2015) Innovation Activities during Intra-Family Leadership Succession in Family Firms: An Empirical Study from a Socioemotional Wealth Perspective. Journal of Family Business Strategy, 6, 104-118. https://doi.org/10.1016/j.jfbs.2014.11.002

[2] Handler, W.C. (1994) Succession in Family Business: A Review of the Research. Family Business Review, 7, 133-157. https://doi.org/10.1111/j.1741-6248.1994.00133.x

[3] Kraiczy, N.D., Hack, A. and Kellermanns, F.W. (2015) What Makes a Family Firm Innovative? CEO Risk-Taking Propensity and the Organizational Context of Family Firms. Journal of Product Innovation Management, 32, 334-348. https://doi.org/10.1111/jpim.12203

[4] Chrisman, J.J., Chua, J.H. and Sharma, P. (2005) Trends and Directions in the Development of a Strategic Management Theory of the Family Firm. Entrepreneurship Theory and Practice, 29, 555-576. https://doi.org/10.1111/j.1540-6520.2005.00098.x

[5] Giambatista, R.C., Rowe, W.G. and Riaz, S. (2005) Nothing Succeeds like Succession: A Critical Review of Leader Succession Literature since 1994. Leadership Quarterly, 16, 963-991. https://doi.org/10.1016/j.leaqua.2005.09.005

[6] Suess-Reyes, J. and Fuetsch, E. (2016) The Future of Family Farming: A Literature Review on Innovative, Sustainable and Succession-Oriented Strategies. Journal of Rural Studies, 47, 117-140. https://doi.org/10.1016/j.jrurstud.2016.07.008

[7] Letonja, M. and Duh, M. (2016) Knowledge Transfer in Family Businesses and Its Effects on the Innovativeness of the Next Family Generation. Knowledge Management Research \& Practice, 14, 213-224. https://doi.org/10.1057/kmrp.2015.25

[8] De Massis, A., Frattini, F. and Lichtenthaler, U. (2013) Research on Technological Innovation in Family Firms: Present Debates and Future Directions. Family Business Review, 26, 10-31. https://doi.org/10.1177/0894486512466258

[9] De Massis, A., et al. (2014) Ability and Willingness as Sufficiency Conditions for Family-Oriented Particularistic Behavior: Implications for Theory and Empirical Studies. Journal of Small Business Management, 52, 344-364.

https://doi.org/10.1111/jsbm.12102

[10] Chrisman, J.J. and Patel, P.C. (2012) Variations in R\&D Investments of Family and Nonfamily Firms: Behavioral Agency and Myopic Loss Aversion Perspectives. 
Academy of Management Journal, 55, 976-997.

https://doi.org/10.5465/amj.2011.0211

[11] Brockhaus, R.H. (2004) Family Business Succession: Suggestions for Future Research. Family Business Review, 17, 165-177. https://doi.org/10.1111/j.1741-6248.2004.00011.x

[12] Kellermanns, F.W., et al. (2008) An Exploratory Study of Family Member Characteristics and Involvement: Effects on Entrepreneurial Behavior in the Family Firm. Family Business Review, 21, 1-14. https://doi.org/10.1111/j.1741-6248.2007.00107.x

[13] Cragun, O. and Nyberg, A.J. (2014) CEO Succession: A 20 Year Review and Typology. Academy of Management. https://doi.org/10.5465/ambpp.2014.14221abstract

[14] Liu, C., Eubanks, D.L. and Chater, N. (2015) The Weakness of Strong Ties: Sampling Bias, Social Ties, and Nepotism in Family Business Succession. The Leadership Quarterly, 26, 419-435. https://doi.org/10.1016/j.leaqua.2015.02.007

[15] Ganzaroli, A., Fiscato, G. and Pilotti, L. (2006) Does Business Succession Enhance Firms' Innovation Capacity? Results from an Exploratory Analysis in Italian SMEs. Departmental Working Papers. https://doi.org/10.2139/ssrn.944043 